\title{
8 People on low income and unemployed persons
}

\author{
Stefano Borgato, Silvia Maffi \\ and Simone Bosetti
}

\begin{abstract}
For obvious reasons, low-income people constantly face serious difficulties in accessing transport. On one hand, affordability represents a financial burden in purchasing transportation services. On the other, due to the areas in which they tend to live or irregular mobility patterns, low-income people are often forced to purchase a private vehicle, despite having very limited economic resources. This chapter analyses the existing correlation between material poverty and mobility poverty. It also explores how people's mobility behaviour is influenced by their economic status, which is often connected to the range of suitable transport alternatives available. More transport options for low-income people mean greater access to opportunities, higher chances of finding better jobs and ultimately not remaining further excluded from society.
\end{abstract}

\section{Introduction}

Poverty, with the meaning of material deprivation and directly linked to people's disposable income and level of employment, is not only the most widespread form of poverty, but also a multidimensional issue that can be analysed from different perspectives using different indicators. In particular, this chapter establishes the relationship which exists between material poverty, unemployment and poverty in transport. This is achieved while attempting to understand how mobility behaviour and opportunities change due to people's income and social position.

Being able to move and having access to transport entail certain costs. In modern and industrialised economies, the proportion of these costs of a household's budget can be considerable. Certainly, these costs vary according to multiple factors, including employment (commuters tend to spend more on transport than people who don't commute), income (lower-income households tend to spend less in total but more as a proportion of their income than higher income households), vehicle ownership (vehicle owning households tend to spend a greater proportion of their income than zerovehicle households), geography (suburban and rural households spend more 
than urban households) and the quality of local transport options (residents of neighbourhoods with better mobility options tend to spend less than those in automobile-dependent communities) (Litman 2017).

At the same time, it is widely believed that mobility is a key element in terms of economic and social opportunities. The link between mobility and transport disadvantages is profound and has an important impact in shaping quality of life for both individuals and communities. Transport disadvantage and lower levels of access to modes of transport are also linked to social exclusion and poor access to goods, services and jobs. This link can contribute to social exclusion making it difficult for people to fully participate in society (Titheridge et al. 2014; Lucas et al. 2016).

In particular, low-income people constantly face a "transport affordability" problem, i.e. a financial burden when purchasing transportation services, particularly those required to access basic goods and activities such as school, work, healthcare, shopping and social activities. The problem also occurs when a household is forced to consume more travel costs than it can reasonably afford, especially costs relating to car ownership and usage. In this sense, low-income people can often be categorised as 'obliged' to possess a private car. This is either because they live in areas that are generally less well served by transport services or because they tend to have less foreseeable mobility patterns (multiple part-time and irregular jobs, seeking low cost goods and services even if less convenient). This leads to the important concept of 'forced car ownership' (FCO), used to define households who own at least one car despite very limited economic resources (i.e. being materially deprived) (Mattioli 2017).

\section{Material poverty in the European Union}

Tackling material poverty reduction is a key policy component of the Europe 2020 Strategy within the EU's agenda for growth and jobs for the current decade (European Commission 2010). In this sense, the EU's progress in reducing poverty is monitored by the headline indicator "people at risk of poverty or social exclusion" (an AROPE indicator).

This indicator takes into account three different dimensions of poverty:

- $\quad$ People at risk of poverty after social transfers;

- Severely materially deprived people; and

- People living in households with very low work intensity.

According to Eurostat's EU statistics on income and living conditions (EUSILC) (Eurostat 2016), in 2015, almost 119 million people $(23.7 \%$ of the total EU population) were at risk of poverty or social exclusion.

The development of the risk of poverty or social exclusion in the EU over the past decade has been marked by two turning points: in 2009, when the number of people at risk started to rise because of the delayed social effects 
of the economic crisis and, in 2012, when this upward trend reversed. By 2015 , the number of people at risk had almost fallen to the 2008 level, reaching 118.8 million people (Eurostat 2017).

In addition, almost 39 million people, or nearly one third (32.5\%) of all people at risk of poverty or social exclusion, were affected by more than one dimension of poverty over the same period. Another 9.2 million people, or 1 in 12 of those at risk of poverty or social exclusion (7.7\%), were affected by all 3 forms (Eurostat 2017).

That being said, these average figures, calculated as a weighted average of national results, mask considerable variations between EU Member States. In 2015, more than a third of the population was at risk of poverty or social exclusion in three EU Member States: Bulgaria (41.3\%), Romania (37.3\%) and Greece (35.7\%). At the other end of the scale, the lowest shares of persons at risk of poverty or social exclusion were recorded in Finland (16.8\%), the Netherlands (16.4\%), Sweden (16.0\%) and the Czech Republic (14.0\%).

Three southern European countries - Greece, Cyprus and Spain experienced the most substantial increases in their share of people at risk of poverty or social exclusion from 2008 to 2015, ranging from five to eight percentage points (Figures 8.1 and 8.2).

Monetary poverty is the most widespread form of poverty, affecting, in $2015,17.3 \%$ of the EU population, who earned less than $60 \%$ of their respective national median equivalised disposable income, the so-called poverty

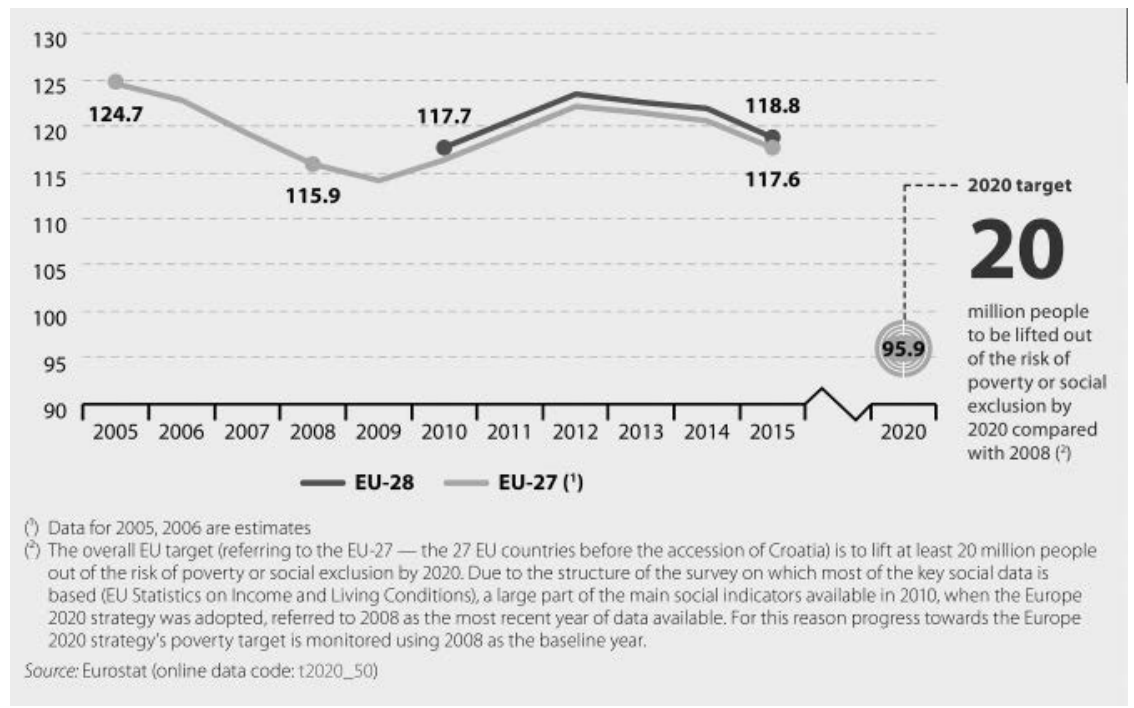

Figure 8.1 People at risk of poverty or social exclusion, EU-27 and EU-28, 20052015 (million people).

Source: Eurostat 2017. 


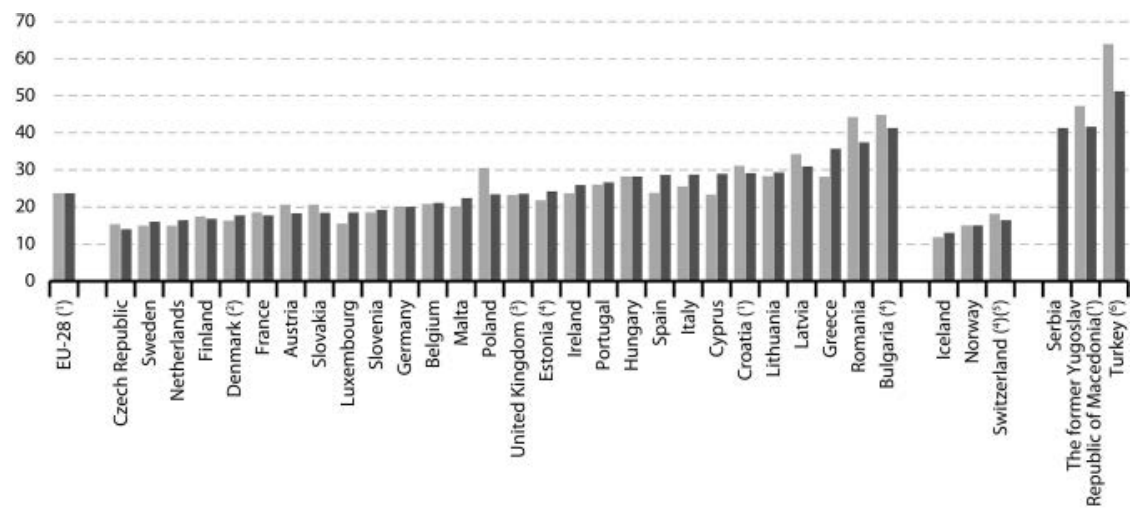

2008

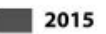

(1) 2010 data (instead of 2008).

(7) Break in time series in 2011 ,

(4) Break in time series in 2014

(5) 2014 data (instead of 2015).

(3) Break in time series in 2012

(9) 2013 data (instead of 2015); break in time series in 2013.

Figure 8.2 People at risk of poverty or social exclusion, by country, in 2008 and 2015 ( $\%$ of population).

Source: Eurostat 2017.

threshold. This represents a slight increase compared with 2008, when $16.5 \%$ fell below this threshold.

The rate for the EU-28, calculated as a weighted average of national results, conceals considerable variations across the EU Member States. In eight Member States, namely Romania (25.4\%), Latvia (22.5\%), Lithuania (22.2\%), Spain (22.1\%), Bulgaria (22.0\%), Estonia (21.6\%), Greece (21.4\%) and Croatia (20.0\%), one fifth or more of the population was identified as being at risk of poverty. Among the Member States, the lowest proportions of persons at risk of poverty were observed in the Czech Republic (9.7\%) and the Netherlands (11.6\%).

Most countries also experienced growth in the number of people below the monetary poverty line, regardless of whether they already had low or high levels of monetary poverty. Increases were most pronounced in Hungary, Sweden and Spain, with rises of between 2.3 and 2.5 percentage points. Croatia, Finland, Austria, the United Kingdom and Latvia were the exception, with monetary poverty in these countries decreasing by $0.6-3.4$ percentage points between 2008 (Croatia: 2010) and 2015.

The differences in poverty rates are more pronounced when the population is classified according to activity status. The unemployed are a particularly vulnerable group: almost half (47.5\%) of all unemployed persons in the EU-28 were at risk of poverty in 2015, with by far the highest rate in Germany (69.1\%), while seven other EU Member States (the three Baltic States, 
Bulgaria, Hungary, Romania and Malta) reported that at least half of those unemployed were at risk of poverty in 2015.

Even among the employed, there is a high risk of social exclusion for workers with low-quality jobs (precarious, low-paid, part-time jobs) resulting in low or no income and a high risk of falling into poverty and material deprivation.

Around one in eight (13.2\%) retired persons in the EU-28 were at risk of poverty in 2015; rates that were at least twice as high as the EU-28 average were recorded in Lithuania (27.6\%), Bulgaria (30.0\%), Latvia (36.7\%) and Estonia (40.1\%).

Those in employment were far less likely to be at risk of poverty (an average of 9.5\% across the whole of the EU-28 in 2015). There was a relatively high proportion of employed persons at risk of poverty in Romania (18.8\%) and to a lesser extent in Greece (13.4\%) and Spain (13.1\%), while Luxembourg, Italy, Poland and Portugal each reported that in excess of 1 in 10 members of their respective workforces were at risk of poverty in 2015.

Paid employment is crucial for ensuring sufficient living standards and it contributes to economic performance, quality of life and social inclusion, making it one of the cornerstones of socioeconomic development and well-being.

In $2016,71.1 \%$ of the EU population aged $20-64$ were employed. This is by far the highest share that has been observed since 2002. However, it is still 3.9 percentage points behind the EU 2020 employment target of $75 \%$. In $2016,6.5 \%$ of the population were unemployed; the remaining $22.5 \%$ were inactive, meaning they were not (actively) looking for work (Eurostat 2018a).

Employment rates across the EU tend to show a north-south divide at a country as well as regional level. Some of the best performing countries such as Germany, Sweden and the United Kingdom also record high regional employment rates.

In Scandinavian and western European countries, employment rates tend to be higher in rural areas. Whereas in most Baltic, southern, central or eastern Member States, cities exhibit higher employment rates.

Considerably lower employment rates are observed for women than men. The gender employment gaps are widest for women in age groups associated with having caring responsibilities for children, dependent family members or grandchildren.

Among the Member States, the lowest unemployment rates in February 2018 were recorded in the Czech Republic (2.4\%), Germany and Malta (both $3.5 \%$ ) as well as Hungary (3.7\% in January 2018). The highest unemployment rates were observed in Greece (20.8\% in December 2017) and Spain (16.1\%) (Figure 8.3).

Youth unemployment rates are generally much higher, even double or more than double, than unemployment rates for all ages. 


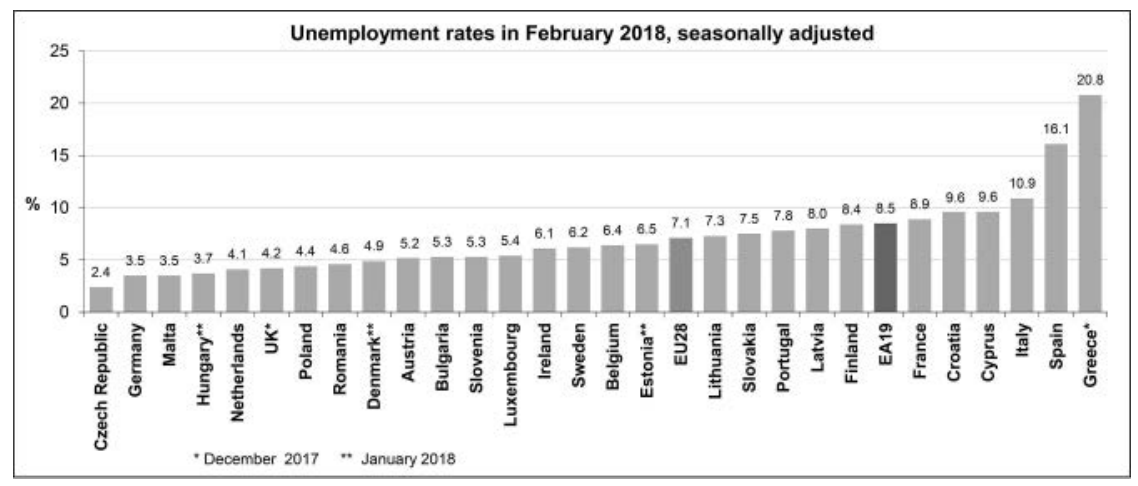

Figure 8.3 Unemployment rates, seasonally adjusted, February 2018 (\%). Source: Eurostat 2018b.

With an unemployment rate of $18.7 \%$ in 2016, young people aged $15-29$ were clearly at a disadvantage compared with the overall population.

Over the past few years, increases in part-time work and fixed-term contracts have been observed. Young people have been the most affected, with $16 \%$ of 15-24-year-olds involuntarily employed on time-limited contracts and $8.4 \%$ involuntarily in part-time work in 2016.

The proportion of people at risk of monetary poverty is also closely linked to income inequality. Data on economic inequality become particularly important for estimating relative poverty because the distribution of economic resources may have a direct bearing on the extent and depth of poverty.

In 2015, there were wide inequalities in the distribution of income: a population-weighted average of national figures for each of the individual EU Member States shows that the top 20\% of the population (with the highest equivalised disposable income) received 5.2 times as much income as the bottom $20 \%$ (with the lowest equivalised disposable income).

This ratio varied considerably across the Member States from 3.5 in Slovakia and the Czech Republic to 6.0 or more in Portugal, Estonia, Latvia, Greece, Spain, Bulgaria and Lithuania, peaking at 8.3 in Romania.

\section{Income-related differences in transport and mobility}

Many researchers, from both North America and Europe, have attempted to understand, from multiple perspectives, the relationship between poverty, low income, unemployment and access to transport (affordability, private car dependence). Not surprisingly, their studies have found that low-income people have less access to private modes of transport and are more likely to 
use public transport. They also tend to travel shorter distances and are more sensitive to public transport fares.

One of the principal results is that low-income and unemployed people are particularly reliant on local public transport services, since in many cases they cannot afford a private car or other means of transport. Unemployed people are the category that is most likely to use public transport: $23 \%$ compared to an average 19\% (European Commission 2014).

A survey showed that while $52 \%$ of people who almost never have difficulties in paying their bills use the car on a daily basis, this percentage goes down to $37 \%$ for those who report difficulties in paying their bills (European Commission 2013).

In terms of car availability, in general the lower the income, the lower the availability of cars (European Commission 2015). Individuals belonging to high-income households do have a higher number of cars available in comparison to those living in low-income households.

On the other hand, those on low income and unemployed living in remote, peripheral or deprived areas often have to rely on private vehicles to access essential services, posing a substantial financial burden on these households. This leads to the already-introduced phenomenon of 'forced car ownership', where households have to own at least one car despite limited economic resources (i.e. being materially deprived). It is assumed that these households potentially trade off motoring expenditure against expenditure in other essential areas. In households with limited resources, the enforced possession and use of a durable good can be the cause of material deprivation, economic stress and vulnerability to fuel price increases. FCO results in households cutting expenditure on other necessities and/or reducing travel activity to the bare minimum, both of which may result in social exclusion. In 2012, 6.7\% of UK households and 5.1\% in Germany were classified as FCO (Mattioli 2017).

When it comes to travel intensity, the average number of trips made per weekday rises with increasing household income. For Londoners with an annual household income of less than $£ 20,000$, the average number of trips per weekday is 2.40 and for Londoners with a household income of below $£ 5,000$, the average number of trips made per weekday is 2.21 , compared to 2.68 for all Londoners (Transport for London 2014).

\section{Mobility challenges for low-income persons}

As seen in the section above, income - either individual or at household level - is highly influential on travel behaviour. The travel behaviour (and transport conditions) of lower income groups has very specific patterns highly differentiated from their higher income counterparts in almost every country of the world (Lucas et al. 2016). A clear recognition of these differences is extremely important for the planning and delivery 
of economically, environmentally and socially sustainable transport systems.

First of all, low-income individuals tend to be less mobile, as they suffer from a lack of both private and public transport services in terms of the number of options and quality of the services available to them. They limit themselves to compulsory trips while other trips, most of the time of a social nature (e.g. visiting friends, relatives), are reduced, if not eliminated (Moore et al. 2013). Such behaviour can be observed worldwide in many countries (Lucas et al. 2016).

At the same time, in urban areas poor people most often live in peripheral locations at the edges of cities with a low amenity value, where there are few local employment opportunities and an absence of local services and basic facilities. Together with limited access to transport options they produce a 'poverty trap', curtailing access to jobs, education, health facilities and social networks (Lucas et al. 2016).

Furthermore, due to budgetary reasons, vulnerable segments often suffer from a lack of access to private and public transport services in terms of both options and quality of service (Barter 1999). They are then forced to rely on walking or cycling, which inevitably reduces the amount and scope of opportunities they can reach. The quality of transport infrastructure (e.g. existence of sidewalks, overall cleanliness or illumination) also tends to be inferior in deprived regions. Hence, low-income groups are often confronted with the need to walk and cycle in unsafe conditions for longer periods and routes. Therefore, there is a higher risk of road casualties and exposure to pollutants with a direct impact on their quality of life and well-being (Titheridge et al. 2014).

It is also important to consider that transport needs and habits depend on a neighbourhood's level of accessibility and social expectation, as it can be experienced particularly in North America. In more accessible neighbourhoods, it may be relatively easy to live without driving a car. Non-motorists do not face social isolation, transport's financial costs tend to be relatively low and driving is considered a convenience. On the contrary, in a more car-dependent neighbourhood, driving is unavoidable, due to scattered destinations, poor alternative travel options and because alternative modes (walking, cycling and public transport) have a bad reputation. In such localities, non-motorists tend to experience social isolation and transport's financial costs are higher. Consequently, lower-income households are relatively poorer and experience more hardship and loss of social esteem (Litman 2003).

Finally, the poorest sections of society do not benefit equally from new or improved mobility services. This may either be because they do not have access to private automobiles or because they cannot afford public transport services. The result is that the poorest population groups may become even further marginalised and sink into poverty (Lucas et al. 2016). 


\section{Conclusions}

This chapter has analysed - from different perspectives - the existing correlation between material poverty and mobility poverty and described how low-income people's social status affects their mobility behaviour, travel choices and ultimately their ability to access opportunities, including school, work, healthcare, shopping, leisure and social activities.

The availability and affordability of means of transport are essential to access these opportunities in order to avoid exclusion from society. However, the necessity of being mobile can represent a serious burden for low-income and unemployed people. As seen in the previous section, it is indisputable that this category of individuals faces several mobility challenges and can be considered transport-disadvantaged in multiple ways.

For this reason, there is an urgent need for transport policymakers to carefully consider targeted interventions aiming at improving accessibility for those on low income and unemployed so that they can have more opportunities for social interactions, higher chances of finding better jobs and ultimately not remain excluded from society.

A first key issue that should be addressed is around the role that the car plays for low-income individuals. On one hand, people who cannot afford a car face significantly higher risks to social exclusion. This is especially true for low-income people living in rural areas where public transport availability is insufficient and distances to services and opportunities are larger than in urban areas. On the other hand, as car ownership is almost unavoidable in certain areas, its forced possession (and usage) poses a significantly high cost burden on already materially deprived individuals. The money spent on mobility is then missing in other essential areas of life, thus threatening even further their poverty status and social exclusion risk.

A second key element to be addressed is related to the role of public transportation and how fundamental this resource is to low-income population groups, especially those living in urban areas. Therefore, activities to promote or enhance such services could certainly have a noteworthy impact on the possibility of low-income individuals to reach opportunities and overcome isolation.

Finally, as experiences of transport disadvantages are often associated with material deprivation, it must be assumed that a large part of those at risk of poverty are also at risk of mobility poverty. However, it is relevant to bear in mind that it is not only material poverty that affects mobility poverty. In fact, the risk of social exclusion is particularly high when materially deprived individuals experience another social disadvantage related, for example, to age, gender, physical condition or migrant/minority status. Experiencing multiple social vulnerabilities, especially when low-income and unemployed people are involved, can definitely aggravate the status of those transport-disadvantaged and raise the risk of social exclusion. 


\section{References}

Barter, Paul A. 1999. "Transport and urban poverty in Asia. A brief introduction to the key issues." In Regional Development Dialogue 20, no. 1: 143-163. http://www. fukuoka.unhabitat.org/docs/occasional_papers/project_a/06/transport-barter-e. html. Accessed 12 June 2018.

European Commission. 2010. "Europe 2020. A strategy for smart, sustainable and inclusive growth" http://ec.europa.eu/eu2020/pdf/COMPLET\%20EN\%20BARR OSO $\% 20 \% 20 \% 20007 \% 20-\% 20$ Europe $\% 202020 \% 20-\% 20$ EN $\% 20$ version.pdf. Accessed 12 June 2018.

European Commission. 2013. "Attitudes of Europeans towards urban mobility." Special Eurobarometer 406/ Wave EB79.4. http://ec.europa.eu/commfrontoffice/ publicopinion/archives/ebs/ebs_406_en.pdf. Accessed 13 June 2018.

European Commission. 2014. "Quality of transport." Report. Special Eurobarometer 422a/Wave EB82.2. http://ec.europa.eu/commfrontoffice/publicopinion/ archives/ebs/ebs_422a_en.pdf. Accessed 13 June 2018.

European Commission. 2015. "EU Survey on issues related to transport and mobility." Joint Research Centre. http://publications.jrc.ec.europa.eu/repository/ bitstream/JRC96151/jrc96151_final\%20version\%202nd\%20correction.pdf. Accessed 13 June 2018.

Eurostat. 2016. "Statistics explained: People at risk of poverty or social exclusion." http://ec.europa.eu/eurostat/statistics-explained/index.php/People_at_risk_of_ poverty_or_social_exclusion. Accessed 20 June 2018.

Eurostat. 2017. "Smarter, greener, more inclusive - indicators to support the Europe 2020 strategy." Luxembourg: Publications Office of the European Union. http://ec.europa.eu/eurostat/documents/3217494/8113874/KS-EZ-17-001-EN-N. pdf/c810af1c-0980-4a3b-bfdd-f6aa4d8a004e. Accessed 13 June 2018.

Eurostat. 2018a. "Statistics explained: Europe 2020 indicators - employment." http://ec.europa.eu/eurostat/statistics-explained/index.php?title=Europe_2020_ indicators_-_employment, updated on 2018. Accessed 13 June 2018.

Eurostat. 2018b. "Euro area unemployment at 8.5\%." https://ec.europa.eu/eurostat/ documents/2995521/8782899/3-04042018-BP-EN.pdf/15f41da1-720e-429b-be25$80 \mathrm{f} 7 \mathrm{~b} 2 \mathrm{fb} 22 \mathrm{~cd}$. Accessed 10 June 2020.

Litman, Todd. 2003. "Social inclusion as a transport planning issue in Canada." Victoria Transport Policy Institute. https://www.researchgate.net/profile/Todd_ Litman/publication/37183839_Social_Inclusion_as_a_transport_planning_ issue_in_Canada/links/544a94ca0cf24b5d6c3ccb25.pdf. Accessed 20 June 2018.

Litman, Todd. 2017. "Transportation affordability. Evaluation and improvement strategies." Victoria Transport Policy Institute. https://www.vtpi.org/affordability. pdf. Accessed 20 September 2020.

Lucas, Karen, Giulio Mattioli, Ersilia Verlinghieri, and Alvaro Guzman. 2016. "Transport poverty and its adverse social consequences." Proceedings of the Institution of Civil Engineers - Transport 169, no. 6: 353-365. https://doi.org/10.1680/ jtran.15.00073.

Mattioli, Giulio. 2017. “'Forced car ownership' in the UK and Germany. Sociospatial patterns and potential economic stress impacts." In Social Inclusion Regional and Urban Mobility: Contribution to Social Inclusion 5, no. 4: 147-160. https://doi.org/10.17645/si.v5i4.1081. 


\section{Stefano Borgato et al.}

Moore, José, Karen Lucas, and John Bates. 2013. "Social disadvantage and transport in the UK. A trip-based approach.” https://www.tsu.ox.ac.uk/pubs/1063moore-lucas-bates.pdf. Accessed 30 March 2020.

Titheridge, Helena, Nicola Christie, Roger Mackett, Daniel Oviedo Hernández, and Runing Ye. 2014. "Transport and poverty. A review of the evidence." https:// www.ucl.ac.uk/transport/sites/transport/files/transport-poverty.pdf. Accessed 30 March 2020.

Transport for London. 2014. "Understanding the travel needs of London's diverse communities. A summary of existing research." http://content.tfl.gov.uk/ understanding-the-travel-needs-of-london-diverse-communities.pdf. Accessed 13 June 2018. 